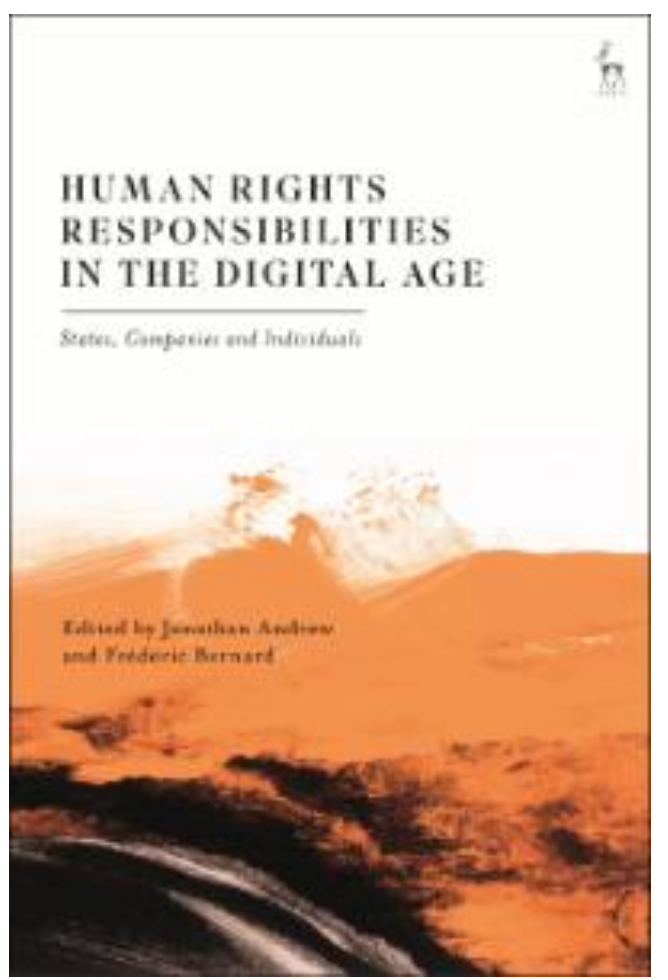

Human Rights Responsibilities in the Digital Age

States, Companies and Individuals

Jonathan Andrew and Frédéric Bernard (eds)

Hart Publishing 2021

Preview Only

The full text of this chapter is only available to members of institutions that have purchased access. If you belong to such an institution, please login or read more about How to Order.

\title{
Chapter 7. Privacy in the Workplace: A Human Rights Due Diligence Approach
}

\author{
Isabel Ebert and Isabelle Wildhaber
}

\section{Extract}

Isabel Ebert Isabelle Wildhaber The workplace traditionally used to be a clearly defined physical place in which employees spent a considerable portion of their working day and has been acknowledged as a central place in which people form social relationships. Despite the many opportunities for remote working provided by digitisation in a range of sectors, until the disruption of the Covid-19 pandemic, most employers required their staff to be physically present in the workplace. Parallel to this recent move towards remote work, business has developed an appetite for data-driven monitoring of work done on-site, from home and remotely. Workplace monitoring measures promise increased efficiency as well as more objective decision making when managing people. The analytical techniques applied rely on a phenomenon witnessed across a range of sectors, the datafication of the workplace: vast amounts of data are available due to increasing data flows stemming from human activity, such as...

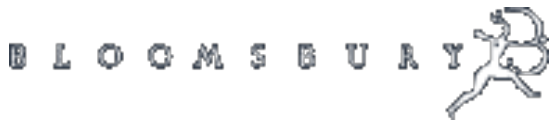

Copyright (C) 2021

Bloomsbury Publishing

Registered in England No. 01984336 